\title{
Androgenetic Alopecia Among Hospital Staff: A Study of Prevalence, Types and a Comparison with General Population in a Secondary Hospital in China
}

\author{
Zhanglei Mu' \\ Yanjun $\mathrm{Gao}^{2}$ \\ Kun $\mathrm{Li}^{1}$ \\ Hualong $\mathrm{Liu}^{3}$ \\ Jianzhong Zhang' \\ 'Department of Dermatology, Peking \\ University People's Hospital, Beijing, \\ People's Republic of China; ${ }^{2}$ Department \\ of Dermatology, Fuping Hospital \\ Affiliated to The Second Hospital of \\ Hebei Medical University, Hebei, People's \\ Republic of China; ${ }^{3}$ Department of \\ Internal Medicine, Fuping Hospital \\ Affiliated to The Second Hospital of \\ Hebei Medical University, Hebei, People's \\ Republic of China
}

Correspondence: Jianzhong Zhang Department of Dermatology, Peking University People's Hospital, No. II Xizhimen South Street, Beijing, 100044, People's Republic of China Tel +86-10-88325472

Email rmzjz@।26.com
Purpose: The aim of this study is to analyze the prevalence and types of androgenetic alopecia (AGA) among hospital staff and compare it with the general population in dermatology.

Subjects and Methods: We carried out the study in a secondary hospital in China. We conducted face-to-face interviews with hospital staff and the outpatients and their accompanying persons (general population) visiting the dermatology clinic of the hospital. The severity of AGA was evaluated using the Hamilton-Norwood and Ludwig classifications.

Results: There were 297 subjects in the hospital staff (105 men and 192 women) and 318 subjects in the general population (109 men and 209 women). The prevalence of AGA among male and female staff was $42.9 \%$ and $13.0 \%$, respectively, and the corresponding rates among general male and female population were $27.5 \%$ and $8.1 \%$, respectively. However, there was no statistical difference in the prevalence of AGA between female staff and general female population. Among male staff, type IV was the most common type of hair loss (17.1\%), and type IVa and type Va were the least common (1.0\%). Among female staff, type I (6.3\%) was the most common type of hair loss, and type III and male pattern hair loss were the least common $(1.0 \%)$. A positive family history was found in $53.3 \%$ of male and $44.0 \%$ of female staff with AGA.

Conclusion: The prevalence of AGA in the male staff was higher than that in the general male population.

Keywords: androgenetic alopecia, China, prevalence, hospital staff

\section{Introduction}

Androgenetic alopecia (AGA) is the most common type of hair loss in men and women. The prevalence of AGA tends to increase with age. Nearly $30 \%$ of Caucasian men will have AGA by the age of 30 years, and $50 \%$ by the age of 50 years. ${ }^{1}$ There are ethnic differences in the prevalence of AGA. Various surveys revealed that the prevalence of AGA is lower in Chinese men and women., ${ }^{2,3}$

Depending on the manifestation of hair loss, AGA is divided into male and female pattern AGA. The male pattern hair loss may appear as recession of the frontal hairline and/or diffuse hair thinning at the vertex, and eventually, only the marginal parietal and occipital hair remains. ${ }^{4}$ Female pattern hair loss typically presents as a diffuse reduction in hair density that mainly affects the mid and frontal regions of the scalp with preservation of the frontal hairline. ${ }^{5}$ Notably, some men might present with female pattern hair loss, and vice versa. 
The exact mechanism of AGA is still unclear. However, genetic predisposition and hormonal status are two major etiological factors of AGA. In patients with a family history of AGA, lifestyle and environmental factors may exacerbate hair loss. ${ }^{6}$ Certain occupations and related factors may be associated with AGA. A previous study showed that the prevalence of AGA in policemen was higher than that in the general population. ${ }^{7}$ Hospital staff, especially physicians and nurses, are often affected by occupation-related factors, which have an impact on many diseases. However, to our knowledge, there are no studies on the prevalence of AGA among hospital staff. Therefore, we investigated the prevalence of AGA in the staff of a hospital in China and compared it with the general population.

\section{Materials and Methods}

We conducted a survey from September 2020 to November 2020 at Fuping Hospital affiliated to The Second Hospital of Hebei Medical University. Verbal informed consent was obtained from all participants, and this, as well as the study protocol, was approved by the Ethics Committee of Fuping Hospital in accordance with the Declaration of Helsinki.

Fuping Hospital is a secondary hospital located in Fuping County, Baoding City, Hebei Province, China. Fuping County has a population of 230,400. The hospital has 352 staff members and the strongest medical capacity in the county. The staff included physicians, nurses, pharmacists, laboratory staff, administrative staff, security guards, maintenance workers, drivers, cleaning staff and laundry staff. In this study, we performed face-to-face interviews with hospital staff. Simultaneously, outpatients (without complaints of hair loss) and accompanying persons who visited the dermatology clinic and were between 20 and 65 years of age were consecutively enrolled as the general population.

We recorded the information, including age, sex, working years, medical history, menstrual history and childbearing history in women, and family history of AGA. The type of AGA was evaluated using the HamiltonNorwood and Ludwig classifications. ${ }^{4,5}$ According to previous study, types I and II male pattern AGA were defined as normal in the Hamilton-Norwood classification. ${ }^{2}$ Subjects with hair loss due to a different reason, including tinea capitis, acute and chronic telogen effluvium, alopecia areata, and cicatricial alopecia, were excluded from the study. The undetermined cases were diagnosed using trichoscopy.

\section{Statistical Analysis}

The age- and gender-adjusted prevalences of AGA were calculated based on China Population Composition in 2019. Statistical analysis was performed using Student's $t$-test, chisquare test, Fisher's exact test or Wilcoxon rank-sum test as appropriate. A P value of $<0.05$ was considered statistically significant. All data were analyzed using Stata/SE version 15.1 (Stata Corp., TX, USA). Prism 9 (GraphPad Software Inc., San Diego, CA, USA) was used to plot the graph.

\section{Results}

A total of 297 subjects (105 men and 192 women) were included in the staff and 318 subjects (109 men and 209 women) in the general population. The response rate was $84.4 \%$ in the hospital staff. The descriptive characteristics of the study population are reported in Table 1. No significant differences were observed in data, including sex ratio, age, duration and family history of AGA, between the staff and general population. The overall prevalence of AGA was $23.6 \%$ and $14.8 \%$ in staff and general population, respectively. The prevalence of AGA in the male staff $(42.9 \%)$ was higher than that in the general male population $(27.5 \%)(\mathrm{P}=0.019)$. However, there was no statistically significant difference in the prevalence of AGA between women in the staff $(13.0 \%)$ and general population $(8.1 \%)$ (Figure 1) $(\mathrm{P}=0.110)$.

The prevalence of AGA in male staff was $42.9 \%$ (95\% confidence interval [CI], 33.4\%-52.3\%; Table 2) with $13.3 \%$ in the third decade, $30.8 \%$ in the fourth decade, $50.0 \%$ in the fifth decade, $56.3 \%$ in the sixth decade, and $66.7 \%$ in men aged $60-65$ years. Therefore, the prevalence increased rapidly from the fourth decade. The most common form of hair loss was type IV (17.1\%), followed by type IIIv (10.5\%), type V (5.7\%), and female pattern hair loss $(1.9 \%)$. However, type IVa and type Va were the least common $(1.0 \%)$. Notably, the most common type of hair loss for each age group was as follows: type IIIv in the third and fourth decade, type IV in the fifth and sixth, and type $\mathrm{V}$ in $60-65$ years.

In the female staff, the prevalence of AGA was $13.0 \%$ (95\% CI, 8.3\%-17.8\%; Table 3). The prevalence of AGA increased with age with $5.4 \%$ in the third decade, $8.2 \%$ in the fourth decade, $15.9 \%$ in the fifth decade, $37.5 \%$ in the sixth decade, and $33.3 \%$ in female aged $60-65$ years. Type I $(6.3 \%)$ was the most common in all age groups, and type III and male pattern were the least common types of AGA (1.0\%). 
Table I Demographic Characteristics of Hospital Staff and the General Population

\begin{tabular}{|c|c|c|c|}
\hline & $\begin{array}{l}\text { Hospital Staff } \\
(n=297)\end{array}$ & $\begin{array}{l}\text { General Population } \\
(n=3 \mid 8)\end{array}$ & $P$-value \\
\hline \multicolumn{4}{|l|}{ Sex } \\
\hline Men & $105(35.4 \%)$ & 109 (34.3\%) & 0.779 \\
\hline Women & $192(64.6 \%)$ & 209 (65.7\%) & \\
\hline \multicolumn{4}{|l|}{ Age } \\
\hline Men & $42.8 \pm 11.4$ & $40.0 \pm 10.3$ & 0.059 \\
\hline Women & $43.0 \pm 9.4$ & $39.2 \pm 11.3$ & 0.400 \\
\hline \multicolumn{4}{|c|}{ Prevalence of AGA } \\
\hline Men & $42.9 \%$ & $27.5 \%$ & 0.019 \\
\hline Women & $13.0 \%$ & $8.1 \%$ & 0.110 \\
\hline \multicolumn{4}{|c|}{ Duration of $A G A$, years (mean $\pm S D$ ) } \\
\hline Men & $11.6 \pm 8.4$ & $9.8 \pm 6.3$ & 0.482 \\
\hline Women & $10.2 \pm 4.3$ & $10.9 \pm 9.1$ & 0.520 \\
\hline \multicolumn{4}{|c|}{ Family history of AGA } \\
\hline Men & $53.3 \%$ & $46.7 \%$ & 0.641 \\
\hline Women & $44.0 \%$ & $47.1 \%$ & 1.000 \\
\hline
\end{tabular}

Table 4 shows a positive family history in $53.3 \%$ and $44.0 \%$ of male and female staff with AGA, respectively. No differences were seen in the positive family history between the two groups $(\mathrm{P}=0.618)$.

\section{Discussion}

Although AGA, as a common hair loss disorder, does not have much impact on health, it seriously affects people's quality of life. Many studies have assessed the prevalence and types of AGA in the general population; however, only one study evaluated these on subjects with a certain

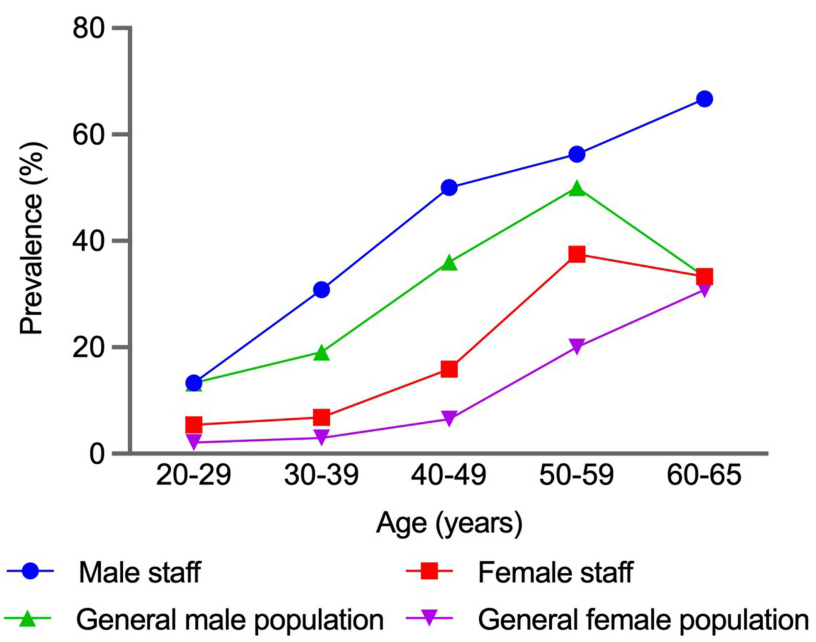

Figure I Prevalence of AGA in hospital staff and the general population. occupation. ${ }^{7}$ To the best of our knowledge, this is the first study on prevalence and types of AGA in hospital staff. The study showed that the prevalence of AGA was higher in male staff compared to that in the general male population.

According to previous community- or populationbased studies, there were ethnic and regional differences in the prevalence of AGA. A US study on predominantly Caucasian men found that the prevalence of AGA between the ages of 18 and 49 years was $40 \% .{ }^{8}$ In Turkey, the prevalence of AGA in men was $47.6 \%$ and that in women was $19.17 \%{ }^{9}$ In African population, the prevalence of AGA in men was $14.6 \%$ and that in women was $3.5 \%{ }^{10}$ An Indian population-based study showed that the prevalence of AGA in men aged 30-50 years was 58\%. ${ }^{11}$ A Thai study found that the prevalence of AGA in Thai and Chinese men was $38.52 \% .{ }^{12}$ In Singapore, the prevalence of AGA in men was $63 \%$. Studies revealed that the prevalence of AGA in Indian population was higher than that of Chinese population ( $87 \%$ vs $61 \%) .{ }^{13}$

There have been some studies on the prevalence of AGA in China. ${ }^{2,3}$ These studies reported that the prevalence of AGA in men was $19.9 \%$ in Shanghai and $21.3 \%$ in six other cities in China; whereas, in women, the prevalence of AGA was 3.1\% in Shanghai and $6.0 \%$ in the six other cities. However, in comparison with previous studies, the prevalence of AGA in the present study was higher in both men and women in staff and general population after standardization. This difference in 
Table 2 The Prevalence and Types of AGA in Male Staff

\begin{tabular}{|c|c|c|c|c|c|c|}
\hline \multirow[t]{2}{*}{ Type } & \multicolumn{6}{|c|}{ Age (Years) } \\
\hline & $20-29(n=15)$ & $30-39(n=26)$ & $40-49(n=36)$ & $50-59(n=16)$ & $60-65(n=12)$ & Total $(n=105)$ \\
\hline III, n (\%) & 0 & I (3.8) & I (2.8) & 0 & 0 & $2(1.9)$ \\
\hline$\| l l v, n$ (\%) & $2(13.3)$ & $4(15.4)$ & $4(11.1)$ & I (6.3) & 0 & II (I0.5) \\
\hline IIla, n (\%) & 0 & 0 & $2(5.6)$ & 0 & 0 & $2(1.9)$ \\
\hline IV, n (\%) & 0 & $3(11.5)$ & $7(19.4)$ & $5(31.3)$ & $3(25.0)$ & $18(17.1)$ \\
\hline IVa, n (\%) & 0 & 0 & I (2.8) & 0 & 0 & I (I.0) \\
\hline $\mathrm{V}, \mathrm{n}(\%)$ & 0 & 0 & I (2.8) & I (6.3) & $4(33.3)$ & $6(5.7)$ \\
\hline Va, n (\%) & 0 & 0 & 0 & I (6.3) & 0 & I (I.0) \\
\hline VI, n (\%) & 0 & 0 & I (2.8) & I (6.3) & 0 & $2(1.9)$ \\
\hline Female pattern, $n(\%)$ & 0 & 0 & I (2.8) & 0 & I (8.3) & $2(1.9)$ \\
\hline Total, n (\%, 95\% Cl) & $2(13.3,-3.9-30.5)$ & $8(30.8,13.0-48.5)$ & $18(50.0,33.7-66.3)$ & $9(56.3,31.9-80.6)$ & $8(66.7,40.0-93.3)$ & $45(42.9,33.4-52.3)$ \\
\hline
\end{tabular}

Table 3 The Prevalence and Types of AGA in Female Staff

\begin{tabular}{|c|c|c|c|c|c|c|}
\hline \multirow[t]{2}{*}{ Type } & \multicolumn{6}{|c|}{ Age (Years) } \\
\hline & $20-29(n=37)$ & $30-39(n=73)$ & $40-49(n=63)$ & $50-59(n=16)$ & $60-65(n=3)$ & Total $(n=192)$ \\
\hline $\mathrm{I}, \mathrm{n}(\%)$ & $2(5.4)$ & $3(4.1)$ & $4(6.3)$ & $3(18.8)$ & 0 & $12(6.3)$ \\
\hline II, n (\%) & 0 & I (I.4) & $4(6.3)$ & $3(18.8)$ & I (33.3) & $9(4.7)$ \\
\hline III, n (\%) & 0 & I (I.4) & I (I.6) & 0 & 0 & $2(1.0)$ \\
\hline Male pattern, n (\%) & 0 & I (I.4) & I (I.6) & 0 & 0 & $2(1.0)$ \\
\hline Total, n (\%, 95\% Cl) & $2(5.4,-1.9-12.7)$ & $6(8.2,1.9-14.5)$ & $10(15.9,6.8-24.9)$ & $6(37.5,13.8-61.2)$ & I (33.3, -20.0-86.7) & $25(13.0,8.3-17.8)$ \\
\hline
\end{tabular}

Table 4 Family History of AGA in Affected Male and Female Staff

\begin{tabular}{|l|l|l|l|l|l|l|}
\hline & \multicolumn{6}{|c|}{ Age (Years) } \\
\cline { 2 - 7 } & $\mathbf{2 0 - 2 9}$ & $\mathbf{3 0 - 3 9}$ & $\mathbf{4 0 - 4 9}$ & $\mathbf{5 0 - 5 9}$ & $\mathbf{6 0 - 6 5}$ & Total (\%, 95\% Cl) \\
\hline Men, n (\%) & $0 / 2$ & $4 / 8(50.0)$ & $13 / 18(72.2)$ & $6 / 9(66.7)$ & $1 / 8(12.5)$ & $24 / 45(53.3,38.8-67.9)$ \\
Women, $\mathrm{n}(\%)$ & $1 / 2(50.0)$ & $3 / 6(50.0)$ & $4 / 10(40.0)$ & $3 / 6(50.0)$ & $0 / 1$ & $11 / 25(44.0,24.5-63.5)$ \\
\hline
\end{tabular}

prevalence of AGA in men and women among studies may be mainly related to the differences in the survey methods (hospital-based vs community-based) and the regions where the patients are located. However, considering the similarity in genetic background, the reason for the differences in prevalence of AGA between cities is worth exploring. Therefore, as mentioned previously, the association of AGA with lifestyle, environment, and other similar causes needs to be evaluated in future studies for a better understanding.

Additionally, some hospital-, clinic-, or other placebased studies have been performed to assess the prevalence of AGA. Norwood investigated 1000 male white inpatients and outpatients to evaluate the incidence of male pattern hair loss in different age groups. ${ }^{4}$ Ludwig conducted a study on Caucasian women from various locations, such as dermatology practice, retirement center, clinic and hospital, various doctors' waiting rooms, and beauty shops, and the prevalence of AGA was found to be $19 \% .{ }^{14}$ Furthermore, in another study conducted at a Turkish clinic, the prevalence of AGA in men was $67.1 \%$ and that in women was $23.9 \% .{ }^{15}$ In Korean population undergoing routine medical examinations in one hospital, the prevalence of AGA was $14.1 \%$ in men and 5.6\% in women. ${ }^{16}$ However, the prevalence of AGA in the general population of the present study was lower than that in Caucasian women and Turkish men and women, and higher than that in Korean men and women. Therefore, our results reconfirmed the effects of racial differences in the prevalence of AGA.

In the present study, the most common types of AGA in the staff were type IV and type IIIv in men, and type I in women. These results were consistent with the order of AGA types obtained in the study of prevalence of AGA in six cities of China. However, type IIIv and type VI were 
the most common types of AGA in men in Shanghai. ${ }^{2}$ The prevalence of these types was previously higher than that in Shanghai population. Furthermore, the proportion of female pattern AGA in men ranked fourth (2.9\%); whereas the proportion of male pattern AGA in women was the least $(1.0 \%)$. These results differed from the study in the Shanghai population, which might be related to geographical differences and different study populations.

In the present study, findings on the positive family history in both groups were consistent with that of a previous study in a Shanghai population but higher than that in the six cities in China. ${ }^{2,3}$ However, in contrast to these two studies, no statistical difference was seen in the rate of positive family history between male and female staff with AGA. In the staff, a high rate of positive family history was observed in men aged 30-59 years and women, which was consistent with the previous studies. ${ }^{2,3}$ On the other hand, the low rate of positive family history at 60-65 years may be mainly related to certain factors, such as recall bias.

One of the previous studies revealed that the prevalence of AGA in policemen was twofold higher than that in the general population. ${ }^{7}$ After standardization, the prevalence of AGA in hospital staff was similar to that of the Taiwan policemen (Figure 2), which indicated that AGA might be associated with occupation-related factors. In general, genetics and androgen (dihydrotestosterone) play a pivotal role in the pathogenesis of AGA. Several pathways and factors, including oxidative stress, inflammation, vasculogenesis, and mechanical stress may also be involved. ${ }^{17,18}$ Therefore, environmental exposure and lifestyle factors may influence AGA via the pathways, such as

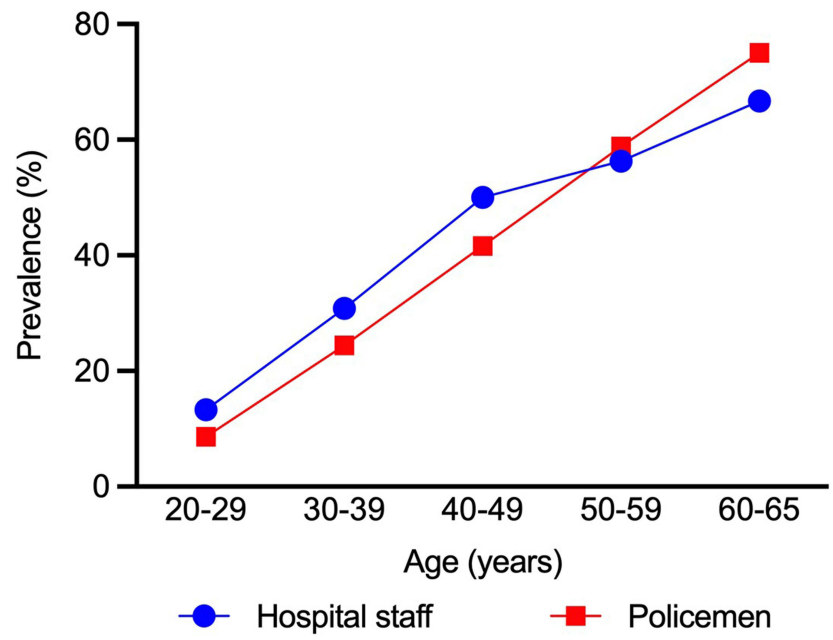

Figure 2 Prevalence of AGA in male staff. Previous study ${ }^{7}$ and present study. oxidative stress. In Taiwan policemen, obesity at a young age and sunlight exposure might also be associated with the higher risk of AGA. ${ }^{7}$ In the Caucasian population, the combination of being overweight and smoking increased the severity of AGA (odds ratio: 5.96; 95\% CI, 1.6521.5). ${ }^{19}$ Another previous study showed that the prevalence of overweight and obese was higher in Scottish nurses than that in individuals in non-health-related occupations. $^{20}$ However, further research is needed to determine whether the higher prevalence of AGA is associated with obesity or other factors in hospital staff.

\section{Limitations}

This study has certain limitations. Although we surveyed almost the entire hospital staff, the sample size of this study is small. Therefore, we did not investigate the risk factors in staff with AGA. In future, we will further expand the sample size to observe and investigate the related risk factors in detail.

\section{Conclusion}

In this hospital-based survey, we studied the prevalence and types of AGA in staff and compared it with general population in the dermatology clinic of the hospital. The results concluded that the prevalence of AGA in male staff was higher than that in general male population; however, the exact reason for this difference is still unclear.

\section{Acknowledgments}

We acknowledge Huixin Liu in Peking University People's Hospital for kind help in statistical analysis.

\section{Disclosure}

The authors report no conflicts of interest in this work.

\section{References}

1. Hamilton JB. Patterned loss of hair in man; types and incidence. Ann NY Acad Sci. 1951;53(3):708-728.

2. Xu F, Sheng YY, Mu ZL, et al. Prevalence and types of androgenetic alopecia in Shanghai, China: a community-based study. Br J Dermatol. 2009;160(3):629-632.

3. Wang TL, Zhou C, Shen YW, et al. Prevalence of androgenetic alopecia in China: a community-based study in six cities. $\mathrm{Br} \mathrm{J}$ Dermatol. 2010;162(4):843-847.

4. Norwood OT. Male pattern baldness: classification and incidence. South Med J. 1975;68(11):1359-1365.

5. Ludwig E. Classification of the types of androgenetic alopecia (common baldness) occurring in the female sex. Br J Dermatol. 1977;97 (3):247-254.

6. Katzer T, Leite Junior A, Beck R, da Silva C. Physiopathology and current treatments of androgenetic alopecia: going beyond androgens and anti-androgens. Dermatol Ther. 2019;32(5):e13059. 
7. Su LH, Chen HH. Androgenetic alopecia in policemen: higher prevalence and different risk factors relative to the general population (KCIS no. 23). Arch Dermatol Res. 2011;303(10):753-761.

8. Rhodes T, Girman CJ, Savin RC, et al. Prevalence of male pattern hair loss in 18-49 year old men. Dermatol Surg. 1998;24(12):13301332.

9. Bas Y, Seckin HY, Kalkan G, et al. Prevalence and types of androgenetic alopecia in north Anatolian population: a community-based study. J Pak Med Assoc. 2015;65(8):806-809.

10. Khumalo NP, Jessop S, Gumedze F, Ehrlich R. Hairdressing and the prevalence of scalp disease in African adults. $\mathrm{Br} J$ Dermatol. 2007;157(5):981-988.

11. Sehgal VN, Kak R, Aggarwal A, Srivastava G, Rajput P. Male pattern androgenetic alopecia in an Indian context: a perspective study. $J$ Eur Acad Dermatol Venereol. 2007;21(4):473-479.

12. Pathomvanich D, Pongratananukul S, Thienthaworn P, Manoshai S. A random study of Asian male androgenetic alopecia in Bangkok, Thailand. Dermatol Surg. 2002;28(9):804-807.

13. Tang PH, Chia HP, Cheong LL, Koh D. A community study of male androgenetic alopecia in Bishan, Singapore. Singapore Med J. 2000;41(5):202-205.
14. Norwood OT. Incidence of female androgenetic alopecia (female pattern alopecia). Dermatol Surg. 2001;27(1):53-54.

15. Salman KE, Altunay IK, Kucukunal NA, Cerman AA. Frequency, severity and related factors of androgenetic alopecia in dermatology outpatient clinic: hospital-based cross-sectional study in Turkey. An Bras Dermatol. 2017;92(1):35-40.

16. Paik JH, Yoon JB, Sim WY, Kim BS, Kim NI. The prevalence and types of androgenetic alopecia in Korean men and women. $\mathrm{Br} J$ Dermatol. 2001;145(1):95-99.

17. Kash N, Leavitt M, Leavitt A, Hawkins SD, Roopani RB. Clinical patterns of hair loss in men: is dihydrotestosterone the only culprit? Dermatol Clin. 2021;39(3):361-370.

18. Tellez-Segura R. Involvement of mechanical stress in androgenetic alopecia. Int J Trichology. 2015;7(3):95-99.

19. Fortes C, Mastroeni S, Mannooranparampil TJ, Ribuffo M. The combination of overweight and smoking increases the severity of androgenetic alopecia. Int J Dermatol. 2017;56(8):862-867.

20. Kyle RG, Neall RA, Atherton IM. Prevalence of overweight and obesity among nurses in Scotland: a cross-sectional study using the Scottish Health Survey. Int J Nurs Stud. 2016;53:126-133.

\section{Publish your work in this journal}

Clinical, Cosmetic and Investigational Dermatology is an international, peer-reviewed, open access, online journal that focuses on the latest clinical and experimental research in all aspects of skin disease and cosmetic interventions. This journal is indexed on CAS.
The manuscript management system is completely online and includes a very quick and fair peer-review system, which is all easy to use. Visit http://www.dovepress.com/testimonials.php to read real quotes from published authors. 